\title{
Research Article \\ Strong Convergence Theorems for Families of Weak Relatively Nonexpansive Mappings
}

\author{
Yekini Shehu \\ Mathematics Institute, African University of Science and Technology, Abuja, Nigeria \\ Correspondence should be addressed to Yekini Shehu, deltanougt2006@yahoo.com \\ Received 30 September 2010; Revised 25 November 2010; Accepted 15 February 2011 \\ Academic Editor: Jean Pierre Gossez
}

Copyright (C 2011 Yekini Shehu. This is an open access article distributed under the Creative Commons Attribution License, which permits unrestricted use, distribution, and reproduction in any medium, provided the original work is properly cited.

We construct a new Halpern type iterative scheme by hybrid methods and prove strong convergence theorem for approximation of a common fixed point of two countable families of weak relatively nonexpansive mappings in a uniformly convex and uniformly smooth real Banach space using the properties of generalized $f$-projection operator. Using this result, we discuss strong convergence theorem concerning general $\mathrm{H}$-monotone mappings. Our results extend many known recent results in the literature.

\section{Introduction}

Let $E$ be a real Banach space with dual $E^{*}$ and let $C$ be nonempty, closed and convex subset of $E$. A mapping $T: C \rightarrow C$ is called nonexpansive if

$$
\|T x-T y\| \leq\|x-y\|, \quad \forall x, y \in C
$$

A point $x \in C$ is called a fixed point of $T$ if $T x=x$. The set of fixed points of $T$ is denoted by $F(T):=\{x \in C: T x=x\}$.

We denote by $J$ the normalized duality mapping from $E$ to $2^{E^{*}}$ defined by

$$
J(x)=\left\{f \in E^{*}:\langle x, f\rangle=\|x\|^{2}=\|f\|^{2}\right\} .
$$

The following properties of $J$ are well known. (The reader can consult [1-3] for more details).

(1) If $E$ is uniformly smooth, then $J$ is norm-to-norm uniformly continuous on each bounded subset of $E$. 
(2) $J(x) \neq \emptyset, x \in E$.

(3) If $E$ is reflexive, then $J$ is a mapping from $E$ onto $E^{*}$.

(4) If $E$ is smooth, then $J$ is single valued.

Throughout this paper, we denote by $\phi$, the functional on $E \times E$ defined by

$$
\phi(x, y)=\|x\|^{2}-2\langle x, J(y)\rangle+\|y\|^{2}, \quad \forall x, y \in E
$$

From [4], in uniformly convex and uniformly smooth Banach spaces, we have

$$
\left(\|x\|-\|y\|^{2}\right)^{2} \leq \phi(x, y) \leq(\|x\|+\|y\|)^{2}, \quad \forall x, y \in E .
$$

Definition 1.1. Let $C$ be a nonempty subset of $E$ and let $\left\{T_{n}\right\}_{n=0}^{\infty}$ be a countable family of mappings from $C$ into $E$. A point $p \in C$ is said to be a asymptotic fixed point of $\left\{T_{n}\right\}_{n=0}^{\infty}$ if $C$ contains a sequence $\left\{x_{n}\right\}_{n=0}^{\infty}$ which converges weakly to $p$ and $\lim _{n \rightarrow \infty}\left\|x_{n}-T_{n} x_{n}\right\|=0$. The set of asymptotic fixed points of $T$ is denoted by $\widehat{F}\left(\left\{T_{n}\right\}_{n=0}^{\infty}\right)$. We say that $\left\{T_{n}\right\}_{n=0}^{\infty}$ is countable family of relatively nonexpansive mappings (see, e.g., [5]) if the following conditions are satisfied:

(R1) $F\left(\left\{T_{n}\right\}_{n=0}^{\infty}\right) \neq \emptyset$;

(R2) $\phi\left(p, T_{n} x\right) \leq \phi(p, x)$, for all $x \in C, p \in F\left(T_{n}\right), n \geq 0$;

(R3) $\bigcap_{n=0}^{\infty} F\left(T_{n}\right)=\widehat{F}\left(\left\{T_{n}\right\}_{n=0}^{\infty}\right)$.

Definition 1.2. A point $p \in C$ is said to be a strong asymptotic fixed point of $\left\{T_{n}\right\}_{n=0}^{\infty}$ if $C$ contains a sequence $\left\{x_{n}\right\}_{n=0}^{\infty}$ which converges strongly to $p$ and $\lim _{n \rightarrow \infty}\left\|x_{n}-T_{n} x_{n}\right\|=0$. The set of strong asymptotic fixed points of $T$ is denoted by $\widetilde{F}\left(\left\{T_{n}\right\}_{n=0}^{\infty}\right)$. We say that a mapping $\left\{T_{n}\right\}_{n=0}^{\infty}$ is countable family of weak relatively nonexpansive mappings (see, e.g., [5]) if the following conditions are satisfied:

(R1) $F\left(\left\{T_{n}\right\}_{n=0}^{\infty}\right) \neq \emptyset$;

(R2) $\phi\left(p, T_{n} x\right) \leq \phi(p, x)$, for all $x \in C, p \in F\left(T_{n}\right), n \geq 0$;

(R3) $\bigcap_{n=0}^{\infty} F\left(T_{n}\right)=\widetilde{F}\left(\left\{T_{n}\right\}_{n=0}^{\infty}\right)$.

Definition 1.3. Let $C$ be a nonempty subset of $E$ and let $T$ be a mapping from $C$ into $E$. A point $p \in C$ is said to be an asymptotic fixed point of $T$ if $C$ contains a sequence $\left\{x_{n}\right\}_{n=0}^{\infty}$ which converges weakly to $p$ and $\lim _{n \rightarrow \infty}\left\|x_{n}-T x_{n}\right\|=0$. The set of asymptotic fixed points of $T$ is denoted by $\widehat{F}(T)$. We say that a mapping $T$ is relatively nonexpansive (see, e.g., [6-11]) if the following conditions are satisfied:

(R1) $F(T) \neq \emptyset$;

(R2) $\phi(p, T x) \leq \phi(p, x)$, for all $x \in C, p \in F(T)$;

(R3) $F(T)=\widehat{F}(T)$.

Definition 1.4. A point $p \in C$ is said to be an strong asymptotic fixed point of $T$ if $C$ contains a sequence $\left\{x_{n}\right\}_{n=0}^{\infty}$ which converges strongly to $p$ and $\lim _{n \rightarrow \infty}\left\|x_{n}-T x_{n}\right\|=0$. The set of strong 
asymptotic fixed points of $T$ is denoted by $\widetilde{F}(T)$. We say that a mapping $T$ is weak relatively nonexpansive (see, e.g., $[12,13]$ ) if the following conditions are satisfied:

(R1) $F(T) \neq \emptyset$;

(R2) $\phi(p, T x) \leq \phi(p, x)$, for all $x \in C, p \in F(T)$;

(R3) $F(T)=\widetilde{F}(T)$.

Definition 1.3 (Definition 1.4, resp.) is a special form of Definition 1.1 (Definition 1.2, resp.) as $T_{n} \equiv T$, for all $n \geq 0$. Furthermore, Su et al. [5] gave an example which is a countable family of weak relatively nonexpansive mappings but not a countable family of relatively nonexpansive mappings. It is obvious that relatively nonexpansive mapping is weak relatively nonexpansive mapping. In fact, for any mapping $T: C \rightarrow C$, we have $F(T) \subset$ $\widetilde{F}(T) \subset \widehat{F}(T)$. Therefore, if $T$ is relatively nonexpansive mapping, then $F(T)=\widetilde{F}(T)=\widehat{F}(T)$. Kang et al. [12] gave an example of a weak relatively nonexpansive mapping which is not relatively nonexpansive.

In [9], Matsushita and Takahashi introduced a hybrid iterative scheme for approximation of fixed points of relatively nonexpansive mapping in a uniformly convex real Banach space which is also uniformly smooth: $x_{0} \in C$,

$$
\begin{gathered}
y_{n}=J^{-1}\left(\alpha_{n} J x_{n}+\left(1-\alpha_{n}\right) J T x_{n}\right), \\
H_{n}=\left\{w \in C: \phi\left(w, y_{n}\right) \leq \phi\left(w, x_{n}\right)\right\}, \\
W_{n}=\left\{w \in C:\left\langle x_{n}-w, J x_{0}-J x_{n}\right\rangle \geq 0\right\}, \\
x_{n+1}=\prod_{H_{n} \cap W_{n}} x_{0}, \quad n \geq 0 .
\end{gathered}
$$

They proved that $\left\{x_{n}\right\}_{n=0}^{\infty}$ converges strongly to $\Pi_{F(T)} x_{0}$, where $F(T) \neq \emptyset$.

In [14], Plubtieng and Ungchittrakool introduced the following hybrid projection algorithm for a pair of relatively nonexpansive mappings: $x_{0} \in C$,

$$
\begin{gathered}
z_{n}=J^{-1}\left(\beta_{n}^{(1)} J x_{n}+\beta_{n}^{(2)} J T x_{n}+\beta_{n}^{(3)} J S x_{n}\right), \\
y_{n}=J^{-1}\left(\alpha_{n} J x_{0}+\left(1-\alpha_{n}\right) J z_{n}\right), \\
C_{n}=\left\{z \in C: \phi\left(z, y_{n}\right) \leq \phi\left(z, x_{n}\right)+\alpha_{n}\left(\left\|x_{0}\right\|^{2}+2\left\langle w, J x_{n}-J x_{0}\right\rangle\right)\right\}, \\
Q_{n}=\left\{z \in C:\left\langle x_{n}-z, J x_{n}-J x_{0}\right\rangle \leq 0\right\}, \\
x_{n+1}=P_{C_{n} \cap Q_{n}} x_{0},
\end{gathered}
$$

where $\left\{\alpha_{n}\right\},\left\{\beta_{n}^{(1)}\right\},\left\{\beta_{n}^{(2)}\right\}$ and $\left\{\beta_{n}^{(3)}\right\}$ are sequences in $(0,1)$ satisfying $\beta_{n}^{(1)}+\beta_{n}^{(2)}+\beta_{n}^{(3)}=1$ and $T$ and $S$ are relatively nonexpansive mappings and $J$ is the single-valued duality mapping on $E$. They proved under the appropriate conditions on the parameters that the sequence $\left\{x_{n}\right\}$ generated by (1.6) converges strongly to a common fixed point of $T$ and $S$.

Recently, Li et al. [15] introduced the following hybrid iterative scheme for approximation of fixed points of a relatively nonexpansive mapping using the properties 
of generalized $f$-projection operator in a uniformly smooth real Banach space which is also uniformly convex: $x_{0} \in C$,

$$
\begin{gathered}
y_{n}=J^{-1}\left(\alpha_{n} J x_{n}+\left(1-\alpha_{n}\right) J T x_{n}\right), \\
C_{n+1}=\left\{w \in C_{n}: G\left(w, J y_{n}\right) \leq G\left(w, J x_{n}\right)\right\}, \\
x_{n+1}=\Pi_{C_{n+1}}^{f} x_{0}, \quad n \geq 1 .
\end{gathered}
$$

They proved a strong convergence theorem for finding an element in the fixed points set of $T$. We remark here that the results of Li et al. [15] extended and improved on the results of Matsushita and Takahashi, [9].

Quite recently, motivated by the results of Matsushita and Takahashi [9] and Plubtieng and Ungchittrakool [14], Su et al. [5] proved the following strong convergence theorem by Halpern type hybrid iterative scheme for approximation of common fixed point of two countable families of weak relatively nonexpansive mappings in uniformly convex and uniformly smooth Banach space.

Theorem 1.5. Let $E$ be a uniformly convex real Banach space which is also uniformly smooth. Let $C$ be a nonempty, closed and convex subset of E. Suppose $\left\{T_{n}\right\}_{n=1}^{\infty}$ and $\left\{S_{n}\right\}_{n=1}^{\infty}$ are two countable families of weak relatively nonexpansive mappings of $C$ into itself such that $F:=\left(\left(\bigcap_{n=1}^{\infty} F\left(S_{n}\right)\right)_{n=1}^{\infty} F\left(T_{n}\right)\right) \cap$ $\left(\bigcap_{n=1}^{\infty} F\left(S_{n}\right)\right) \neq \emptyset$. Suppose $\left\{x_{n}\right\}_{n=0}^{\infty}$ is iteratively generated by $x_{0} \in C$,

$$
\begin{gathered}
z_{n}=J^{-1}\left(\beta_{n}^{(1)} J x_{0}+\beta_{n}^{(2)} J T_{n} x_{n}+\beta_{n}^{(3)} J S_{n} x_{n}\right), \\
y_{n}=J^{-1}\left(\alpha_{n} J z_{n}+\left(1-\alpha_{n}\right) J x_{n}\right), \\
C_{n}=\left\{w \in C_{n-1} \cap Q_{n-1}: \phi\left(w, y_{n}\right) \leq\left(1-\alpha_{n} \beta_{n}^{(1)}\right) \phi\left(w, x_{n}\right)+\alpha_{n} \beta_{n}^{(1)} \phi\left(w, x_{0}\right)\right\}, \\
C_{0}=\left\{w \in C: \phi\left(w, y_{0}\right) \leq \phi\left(w, x_{0}\right)\right\}, \\
Q_{n}=\left\{w \in C_{n-1} \cap Q_{n-1}:\left\langle x_{n}-w, J x_{0}-J x_{n}\right\rangle \geq 0\right\}, \\
Q_{0}=C, \\
x_{n+1}=\prod_{C_{n} \cap Q_{n}} x_{0}, \quad n \geq 1,
\end{gathered}
$$

with the conditions

(i) $\lim _{n \rightarrow \infty} \beta_{n}^{(1)}=0$;

(ii) $\lim \sup _{n \rightarrow \infty} \beta_{n}^{(2)} \beta_{n}^{(3)}>0$.

Then, $\left\{x_{n}\right\}_{n=0}^{\infty}$ converges strongly to $\Pi_{F} x_{0}$.

Motivated by the above mentioned results and the ongoing research, it is our purpose in this paper to prove a strong convergence theorem by Halpern type iterative scheme for two countable families of weak relatively nonexpansive mappings in a uniformly convex and uniformly smooth real Banach space using the properties of generalized $f$-projection operator. Our results extend the results of Su et al. [5] and many other recent known results in the literature. 


\section{Preliminaries}

Let $E$ be a real Banach space. The modulus of smoothness of $E$ is the function $\rho_{E}:[0, \infty) \rightarrow$ $[0, \infty)$ defined by

$$
\rho_{E}(t):=\sup \left\{\frac{1}{2}(\|x+y\|+\|x-y\|)-1:\|x\| \leq 1,\|y\| \leq t\right\}
$$

$E$ is uniformly smooth if and only if

$$
\lim _{t \rightarrow 0} \frac{\rho_{E}(t)}{t}=0
$$

Let $\operatorname{dim} E \geq 2$. The modulus of convexity of $E$ is the function $\delta_{E}:(0,2] \rightarrow[0,1]$ defined by

$$
\delta_{E}(\epsilon):=\inf \left\{1-\left\|\frac{x+y}{2}\right\|:\|x\|=\|y\|=1 ; \epsilon=\|x-y\|\right\}
$$

$E$ is uniformly convex if for any $\epsilon \in(0,2]$, there exists a $\delta=\delta(\epsilon)>0$ such that if $x, y \in E$ with $\|x\| \leq 1,\|y\| \leq 1$ and $\|x-y\| \geq \epsilon$, then $\|(1 / 2)(x+y)\| \leq 1-\delta$. Equivalently, $E$ is uniformly convex if and only if $\delta_{E}(\epsilon)>0$ for all $\epsilon \in(0,2]$. A normed space $E$ is called strictly convex if for all $x, y \in E, x \neq y,\|x\|=\|y\|=1$, we have $\|\lambda x+(1-\lambda) y\|<1$, for all $\lambda \in(0,1)$.

Let $E$ be a smooth, strictly convex, and reflexive real Banach space and let $C$ be a nonempty, closed, and convex subset of $E$. Following Alber [16], the generalized projection $\Pi_{C}$ from $E$ onto $C$ is defined by

$$
\Pi_{C}(x):=\arg \min _{y \in C} \phi(y, x), \quad \forall x \in E .
$$

The existence and uniqueness of $\Pi_{C}$ follows from the property of the functional $\phi(x, y)$ and strict monotonicity of the mapping $J$ (see, e.g., $[3,4,16-18]$ ). If $E$ is a Hilbert space, then $\Pi_{C}$ is the metric projection of $H$ onto $C$.

Next, we recall the concept of generalized $f$-projector operator, together with its properties. Let $G: C \times E^{*} \rightarrow \mathbb{R} \cup\{+\infty\}$ be a functional defined as follows:

$$
G(\xi, \varphi)=\|\xi\|^{2}-2\langle\xi, \varphi\rangle+\|\varphi\|^{2}+2 \rho f(\xi),
$$

where $\xi \in C, \varphi \in E^{*}, \rho$ is a positive number and $f: C \rightarrow \mathbb{R} \cup\{+\infty\}$ is proper, convex, and lower semicontinuous. From the definitions of $G$ and $f$, it is easy to see the following properties:

(i) $G(\xi, \varphi)$ is convex and continuous with respect to $\varphi$ when $\xi$ is fixed;

(ii) $G(\xi, \varphi)$ is convex and lower semicontinuous with respect to $\xi$ when $\varphi$ is fixed. 
Definition 2.1 (Wu and Huang [19]). Let $E$ be a real Banach space with its dual $E^{*}$. Let $C$ be a nonempty, closed, and convex subset of $E$. We say that $\Pi_{C}^{f}: E^{*} \rightarrow 2^{C}$ is a generalized $f$-projection operator if

$$
\Pi_{C}^{f} \varphi=\left\{u \in C: G(u, \varphi)=\inf _{\xi \in C} G(\xi, \varphi)\right\}, \quad \forall \varphi \in E^{*}
$$

For the generalized $f$-projection operator, $\mathrm{Wu}$ and Huang [19] proved the following theorem basic properties.

Lemma 2.2 (Wu and Huang [19]). Let E be a real reflexive Banach space with its dual $E^{*}$. Let $C$ be a nonempty, closed, and convex subset of $E$. Then the following statements hold:

(i) $\Pi_{C}^{f}$ is a nonempty closed convex subset of $C$ for all $\varphi \in E^{*}$;

(ii) if $E$ is smooth, then for all $\varphi \in E^{*}, x \in \Pi_{C}^{f}$ if and only if

$$
\langle x-y, \varphi-J x\rangle+\rho f(y)-\rho f(x) \geq 0, \quad \forall y \in C ;
$$

(iii) if $E$ is strictly convex and $f: C \rightarrow \mathbb{R} \cup\{+\infty\}$ is positive homogeneous (i.e., $f(t x)=t f(x)$ for all $t>0$ such that $t x \in C$ where $x \in C)$, then $\Pi_{C}^{f}$ is a single valued mapping.

Fan et al. [20] showed that the condition $f$ is positive homogeneous which appeared in Lemma 2.2 can be removed.

Lemma 2.3 (Fan et al. [20]). Let $E$ be a real reflexive Banach space with its dual $E^{*}$ and $C$ a nonempty, closed and convex subset of $E$. Then if $E$ is strictly convex, then $\Pi_{C}^{f}$ is a single valued mapping.

Recall that $J$ is a single valued mapping when $E$ is a smooth Banach space. There exists a unique element $\varphi \in E^{*}$ such that $\varphi=J x$ for each $x \in E$. This substitution in (4.3) gives

$$
G(\xi, J x)=\|\xi\|^{2}-2\langle\xi, J x\rangle+\|x\|^{2}+2 \rho f(\xi)
$$

Now, we consider the second generalized $f$-projection operator in a Banach space.

Definition 2.4. Let $E$ be a real Banach space and $C$ a nonempty, closed and convex subset of $E$. We say that $\Pi_{C}^{f}: E \rightarrow 2^{C}$ is a generalized $f$-projection operator if

$$
\Pi_{C}^{f} x=\left\{u \in C: G(u, J x)=\inf _{\xi \in C} G(\xi, J x)\right\}, \quad \forall x \in E .
$$


Obviously, the definition of $\left\{T_{n}\right\}_{n=0}^{\infty}$ is a countably family of weak relatively nonexpansive mappings is equivalent to

$\left(R^{\prime} 1\right) F\left(\left\{T_{n}\right\}_{n=0}^{\infty}\right) \neq \emptyset$;

$\left(R^{\prime} 2\right) G\left(p, J T_{n} x\right) \leq G(p, J x)$, for all $x \in C, p \in F\left(T_{n}\right), n \geq 0$.

$\left(R^{\prime} 3\right) \bigcap_{n=0}^{\infty} F\left(T_{n}\right)=\tilde{F}\left(\left\{T_{n}\right\}_{n=0}^{\infty}\right)$.

Lemma 2.5 (Li et al. [15]). Let $E$ be a Banach space and $f: E \rightarrow \mathbb{R} \cup\{+\infty\}$ be a lower semicontinuous convex functional. Then there exists $x^{*} \in E^{*}$ and $\alpha \in \mathbb{R}$ such that

$$
f(x) \geq\left\langle x, x^{*}\right\rangle+\alpha, \quad \forall x \in E
$$

We know that the following lemmas hold for operator $\Pi_{C}^{f}$.

Lemma 2.6 (Li et al. [15]). Let $C$ be a nonempty, closed, and convex subset of a smooth and reflexive Banach space E. Then the following statements hold:

(i) $\Pi_{C} x^{f}$ is a nonempty closed, and convex subset of $C$ for all $x \in E$;

(ii) for all $x \in E, \widehat{x} \in \Pi_{C} x^{f}$ if and only if

$$
\langle\widehat{x}-y, J x-J \widehat{x}\rangle+\rho f(y)-\rho f(x) \geq 0, \quad \forall y \in C ;
$$

(iii) if $E$ is strictly convex, then $\Pi_{C} x^{f}$ is a single valued mapping.

Lemma 2.7 (Li et al. [15]). Let $C$ be a nonempty, closed, and convex subset of a smooth and reflexive Banach space E. Let $x \in E$ and $\widehat{x} \in \Pi_{C}^{f} x$. Then

$$
\phi(y, \widehat{x})+G(\widehat{x}, J x) \leq G(y, J x), \quad \forall y \in C .
$$

Lemma 2.8 (Su et al. [5]). Let $C$ be a nonempty, closed, and convex subset of a smooth, strictly convex Banach space $E$. Let $T$ be a weak relatively nonexpansive mapping of $C$ into itself. Then $F(T)$ is closed and convex.

Also, this following lemma will be used in the sequel.

Lemma 2.9 (Kamimura and Takahashi [4]). Let $C$ be a nonempty, closed and convex subset of a smooth, uniformly convex Banach space E. Let $\left\{x_{n}\right\}_{n=1}^{\infty}$ and $\left\{y_{n}\right\}_{n=1}^{\infty}$ be sequences in E such that either $\left\{x_{n}\right\}_{n=1}^{\infty}$ or $\left\{y_{n}\right\}_{n=1}^{\infty}$ is bounded. If $\lim _{n \rightarrow \infty} \phi\left(x_{n}, y_{n}\right)=0$, then $\lim _{n \rightarrow \infty}\left\|x_{n}-y_{n}\right\|=0$.

Lemma 2.10 (Cho et al. [21]). Let $E$ be a uniformly convex real Banach space. For arbitrary $r>0$, let $B_{r}(0):=\{x \in E:\|x\| \leq r\}$ and $\lambda, \mu, \gamma \in[0,1]$ such that $\lambda+\mu+\gamma=1$. Then, there exists a continuous strictly increasing convex function

$$
g:[0,2 r] \longrightarrow \mathbb{R}, \quad g(0)=0
$$

such that for every $x, y, z \in B_{r}(0)$, the following inequality holds:

$$
\|\lambda x+\mu y+\gamma z\|^{2} \leq \lambda\|x\|^{2}+\mu\|y\|^{2}-\lambda \mu g(\|x-y\|) .
$$


For the rest of this paper, the sequence $\left\{x_{n}\right\}_{n=0}^{\infty}$ converges strongly to $p$ will be denoted by $x_{n} \rightarrow p$ as $n \rightarrow \infty$ and we will assume that $\beta_{n}^{(1)}, \beta_{n}^{(2)}, \beta_{n}^{(3)} \in[0,1]$ such that $\beta_{n}^{(1)}+\beta_{n}^{(2)}+\beta_{n}^{(3)}=$ 1, for all $n \geq 0$.

\section{Main Results}

Theorem 3.1. Let $E$ be a uniformly convex real Banach space which is also uniformly smooth. Let $C$ be a nonempty, closed, and convex subset of E. Suppose $\left\{T_{n}\right\}_{n=0}^{\infty}$ and $\left\{S_{n}\right\}_{n=0}^{\infty}$ are two countable families of weak relatively nonexpansive mappings of $C$ into itself such that $F:=\left(\bigcap_{n=0}^{\infty} F\left(T_{n}\right)\right) \cap$ $\left(\bigcap_{n=0}^{\infty} F\left(S_{n}\right)\right) \neq \emptyset$. Let $f: E \rightarrow \mathbb{R}$ be a convex and lower semicontinuous mapping with $C \subset$ $\operatorname{int}(D(f))$ and suppose $\left\{x_{n}\right\}_{n=0}^{\infty}$ is iteratively generated by $x_{0} \in C, C_{0}=C$,

$$
\begin{gathered}
z_{n}=J^{-1}\left(\beta_{n}^{(1)} J x_{0}+\beta_{n}^{(2)} J T_{n} x_{n}+\beta_{n}^{(3)} J S_{n} x_{n}\right), \\
y_{n}=J^{-1}\left(\alpha_{n} J z_{n}+\left(1-\alpha_{n}\right) J x_{n}\right), \\
C_{n+1}=\left\{w \in C_{n}: G\left(w, J y_{n}\right) \leq\left(1-\alpha_{n} \beta_{n}^{(1)}\right) G\left(w, J x_{n}\right)+\alpha_{n} \beta_{n}^{(1)} G\left(w, J x_{0}\right)\right\}, \\
x_{n+1}=\prod_{C_{n+1}}^{f} x_{0}, \quad n \geq 0,
\end{gathered}
$$

with the conditions

(i) $\lim _{n \rightarrow \infty} \beta_{n}^{(1)}=0$;

(ii) $0<b \leq \beta_{n}^{(2)} \leq 1,0<d \leq \beta_{n}^{(3)} \leq 1$;

(iii) $0<\alpha \leq \alpha_{n} \leq 1$ for some $\alpha \in(0,1)$.

Then, $\left\{x_{n}\right\}_{n=0}^{\infty}$ converges strongly to $\prod_{F}^{f} x_{0}$.

Proof. We first show that $C_{n}$, for all $n \geq 0$ is closed and convex. It is obvious that $C_{0}=C$ is closed and convex. Thus, we only need to show that $C_{n}$ is closed and convex for each $n \geq 1$. Since $G\left(w, J y_{n}\right) \leq\left(1-\alpha_{n} \beta_{n}^{(1)}\right) G\left(w, J x_{n}\right)+\alpha_{n} \beta_{n}^{(1)} G\left(w, J x_{0}\right)$ is equivalent to

$$
2\left(\left\langle w,\left(1-\alpha_{n} \beta_{n}^{(1)}\right) J x_{n}+\alpha_{n} \beta_{n}^{(1)} J x_{0}-J y_{n}\right\rangle\right) \leq\left(1-\alpha_{n} \beta_{n}^{(1)}\right)\left\|x_{n}\right\|^{2}+\alpha_{n} \beta_{n}^{(1)}\left\|x_{0}\right\|^{2}-\left\|y_{n}\right\|^{2}
$$

This implies that $C_{n+1}$ is closed and convex for all $n \geq 0$.

We next show that $F \subset C_{n}$, for all $n \geq 0$. For $n=0$, we have $F \subset C=C_{0}$. Then for each $x^{*} \in F$, we obtain

$$
\begin{aligned}
G\left(x^{*}, J y_{n}\right) & =G\left(x^{*},\left(\alpha_{n} J z_{n}+\left(1-\alpha_{n}\right) J x_{n}\right)\right) \\
& =\left\|x^{*}\right\|^{2}-2 \alpha_{n}\left\langle x^{*}, J z_{n}\right\rangle-2\left(1-\alpha_{n}\right)\left\langle x^{*}, J x_{n}\right\rangle+\left\|\alpha_{n} J z_{n}+\left(1-\alpha_{n}\right) J x_{n}\right\|^{2}+2 \rho f\left(x^{*}\right) \\
& \leq\left\|x^{*}\right\|^{2}-2 \alpha_{n}\left\langle x^{*}, J z_{n}\right\rangle-2\left(1-\alpha_{n}\right)\left\langle x^{*}, J x_{n}\right\rangle+\alpha_{n}\left\|J z_{n}\right\|^{2}+\left(1-\alpha_{n}\right)\left\|J x_{n}\right\|^{2}+2 \rho f\left(x^{*}\right) \\
& =\alpha_{n} G\left(x^{*}, J z_{n}\right)+\left(1-\alpha_{n}\right) G\left(x^{*}, J x_{n}\right) \\
& =\left(1-\alpha_{n}\right) G\left(x^{*}, J x_{n}\right)+\alpha_{n} G\left(x^{*}, \beta_{n}^{(1)} J x_{0}+\beta_{n}^{(2)} J T_{n} x_{n}+\beta_{n}^{(3)} J S_{n} x_{n}\right) \\
& \leq\left(1-\alpha_{n}\right) G\left(x^{*}, J x_{n}\right)
\end{aligned}
$$


Abstract and Applied Analysis

$$
\begin{aligned}
& +\alpha_{n}\left(\left\|x^{*}\right\|^{2}-2 \beta_{n}^{(1)}\left\langle x^{*}, J x_{0}\right\rangle-2 \beta_{n}^{(2)}\left\langle x^{*}, J T_{n} x_{n}\right\rangle-2 \beta_{n}^{(3)}\left\langle x^{*}, J S_{n} x_{n}\right\rangle\right. \\
& \left.+\beta_{n}^{(1)}\left\|x_{0}\right\|^{2}+\beta_{n}^{(2)}\left\|T_{n} x_{n}\right\|^{2}+\beta_{n}^{(3)}\left\|S_{n} x_{n}\right\|^{2}+2 \rho f\left(x^{*}\right)\right) \\
= & \left(1-\alpha_{n}\right) G\left(x^{*}, J x_{n}\right)+\alpha_{n}\left(\beta_{n}^{(1)} G\left(x^{*}, J x_{0}\right)+\beta_{n}^{(2)} G\left(x^{*}, J T_{n} x_{n}\right)+\beta_{n}^{(3)} G\left(x^{*}, J S_{n} x_{n}\right)\right) \\
\leq & \left(1-\alpha_{n}\right) G\left(x^{*}, J x_{n}\right)+\alpha_{n}\left(\beta_{n}^{(1)} G\left(x^{*}, J x_{0}\right)+\beta_{n}^{(2)} G\left(x^{*}, J x_{n}\right)+\beta_{n}^{(3)} G\left(x^{*}, J x_{n}\right)\right) \\
\leq & \left(1-\alpha_{n} \beta_{n}^{(1)}\right) G\left(x^{*}, J x_{n}\right)+\alpha_{n} \beta_{n}^{(1)} G\left(x^{*}, J x_{0}\right) .
\end{aligned}
$$

So, $x^{*} \in C_{n}$. This implies that $F \subset C_{n}$, for all $n \geq 0$. Since $C_{n+1}$ is closed and convex for all $n \geq$ 0 and $\emptyset \neq F \subset C_{n}$, for all $n \geq 0$, it follows that $\Pi_{C_{n+1}}^{f} x_{0}$ is well defined for all $n \geq 0$.

We now show that $\lim _{n \rightarrow \infty} G\left(x_{n}, J x_{0}\right)$ exists. Since $f: E \rightarrow \mathbb{R}$ is a convex and lower semicontinuous, applying Lemma 2.5 , we see that there exists $u^{*} \in E^{*}$ and $\alpha \in \mathbb{R}$ such that

$$
f(y) \geq\left\langle y, u^{*}\right\rangle+\alpha, \quad \forall y \in E .
$$

It follows that

$$
\begin{aligned}
G\left(x_{n}, J x_{0}\right) & =\left\|x_{n}\right\|^{2}-2\left\langle x_{n}, J x_{0}\right\rangle+\left\|x_{0}\right\|^{2}+2 \rho f\left(x_{n}\right) \\
& \geq\left\|x_{n}\right\|^{2}-2\left\langle x_{n}, J x_{0}\right\rangle+\left\|x_{0}\right\|^{2}+2 \rho\left\langle x_{n}, u^{*}\right\rangle+2 \rho \alpha \\
& =\left\|x_{n}\right\|^{2}-2\left\langle x_{n}, J x_{0}-\rho u^{*}\right\rangle+\left\|x_{0}\right\|^{2}+2 \rho \alpha \\
& \geq\left\|x_{n}\right\|^{2}-2\left\|x_{n}\right\|\left\|J x_{0}-\rho u^{*}\right\|+\left\|x_{0}\right\|^{2}+2 \rho \alpha \\
& =\left(\left\|x_{n}\right\|-\left\|J x_{0}-\rho u^{*}\right\|\right)^{2}+\left\|x_{0}\right\|^{2}-\left\|J x_{0}-\rho u^{*}\right\|^{2}+2 \rho \alpha .
\end{aligned}
$$

Since $x_{n}=\Pi_{C_{n}}^{f} x_{0}$, it follows from (3.5) that

$$
G\left(x^{*}, J x_{0}\right) \geq G\left(x_{n}, J x_{0}\right) \geq\left(\left\|x_{n}\right\|-\left\|J x_{0}-\rho u^{*}\right\|\right)^{2}+\left\|x_{0}\right\|^{2}-\left\|J x_{0}-\rho u^{*}\right\|^{2}+2 \rho \alpha
$$

for each $x^{*} \in F$. This implies that $\left\{x_{n}\right\}_{n=0}^{\infty}$ is bounded and so is $\left\{G\left(x_{n}, J x_{0}\right)\right\}_{n=0}^{\infty}$. By the construction of $C_{n}$, we have that $C_{m} \subset C_{n}$ and $x_{m}=\Pi_{C_{m}}^{f} x_{0} \in C_{n}$ for any positive integer $m \geq n$. It then follows Lemma 2.7 that

$$
\phi\left(x_{m}, x_{n}\right)+G\left(x_{n}, J x_{0}\right) \leq G\left(x_{m}, J x_{0}\right) .
$$

It is obvious that

$$
\phi\left(x_{m}, x_{n}\right) \geq\left(\left\|x_{m}\right\|-\left\|x_{n}\right\|\right)^{2} \geq 0
$$


In particular,

$$
\begin{gathered}
\phi\left(x_{n+1}, x_{n}\right)+G\left(x_{n}, J x_{0}\right) \leq G\left(x_{n+1}, J x_{0}\right), \\
\phi\left(x_{n+1}, x_{n}\right) \geq\left(\left\|x_{n+1}\right\|-\left\|x_{n}\right\|\right)^{2} \geq 0,
\end{gathered}
$$

and so $\left\{G\left(x_{n}, J x_{0}\right)\right\}_{n=0}^{\infty}$ is nondecreasing. It follows that the limit of $\left\{G\left(x_{n}, J x_{0}\right)\right\}_{n=0}^{\infty}$ exists.

Now, (3.7) implies that

$$
\phi\left(x_{m}, x_{n}\right) \leq G\left(x_{m}, J x_{0}\right)-G\left(x_{n}, J x_{0}\right) .
$$

Taking the limit as $m, n \rightarrow \infty$ in (3.10), we obtain

$$
\lim _{n \rightarrow \infty} \phi\left(x_{m}, x_{n}\right)=0 .
$$

It then follows from Lemma 2.9 that $\left\|x_{m}-x_{n}\right\| \rightarrow 0$ as $m, n \rightarrow \infty$. Hence, $\left\{x_{n}\right\}_{n=0}^{\infty}$ is Cauchy. Since $E$ is a Banach space and $C$ is closed and convex, then there exists $p \in C$ such that $x_{n} \rightarrow p$ as $n \rightarrow \infty$.

Now since $\phi\left(x_{m}, x_{n}\right) \rightarrow 0$ as $m, n \rightarrow \infty$ we have in particular that $\phi\left(x_{n+1}, x_{n}\right) \rightarrow$ 0 as $n \rightarrow \infty$ and this further implies that $\lim _{n \rightarrow \infty}\left\|x_{n+1}-x_{n}\right\|=0$. Since $x_{n+1}=\Pi_{C_{n+1}}^{f} x_{0} \in C_{n+1}$, we have

$$
\phi\left(x_{n+1}, y_{n}\right) \leq\left(1-\alpha_{n} \beta_{n}^{(1)}\right) \phi\left(x_{n+1}, x_{n}\right)+\alpha_{n} \beta_{n}^{(1)} \phi\left(x_{n+1}, x_{0}\right), \quad \forall n \geq 0
$$

Then, we obtain

$$
\lim _{n \rightarrow \infty} \phi\left(x_{n+1}, y_{n}\right)=0
$$

Since $E$ is uniformly convex and smooth, we have from Lemma 2.9 that

$$
\lim _{n \rightarrow \infty}\left\|x_{n+1}-x_{n}\right\|=0=\lim _{n \rightarrow \infty}\left\|x_{n+1}-y_{n}\right\|
$$

So,

$$
\left\|x_{n}-y_{n}\right\| \leq\left\|x_{n+1}-x_{n}\right\|+\left\|x_{n+1}-y_{n}\right\| \text {. }
$$

Hence,

$$
\lim _{n \rightarrow \infty}\left\|x_{n}-y_{n}\right\|=0
$$

Since $J$ is uniformly norm-to-norm continuous on bounded sets and $\lim _{n \rightarrow \infty}\left\|x_{n}-y_{n}\right\|=0$, we obtain

$$
\lim _{n \rightarrow \infty}\left\|J x_{n}-J y_{n}\right\|=0
$$


Since $0<\alpha \leq \alpha_{n}<1$, then

$$
\left\|J z_{n}-J x_{n}\right\|=\frac{1}{\alpha_{n}}\left\|J x_{n}-J y_{n}\right\| \longrightarrow 0, \quad \text { as } n \rightarrow \infty
$$

Since $J^{-1}$ is uniformly norm-to-norm continuous on bounded sets, we have

$$
\lim _{n \rightarrow \infty}\left\|z_{n}-x_{n}\right\|=0
$$

so that $z_{n} \rightarrow p$ as $n \rightarrow \infty$. Since $\left\{x_{n}\right\}$ is bounded, so are $\left\{z_{n}\right\},\left\{J T_{n} x_{n}\right\}$, and $\left\{J S_{n} x_{n}\right\}$.

Let $r:=\sup _{n \geq 0}\left\{\left\|x_{n}\right\|,\left\|T_{n} x_{n}\right\|,\left\|S_{n} x_{n}\right\|\right\}$. Then from Lemma 2.10, we have

$$
\begin{aligned}
& G\left(x^{*}, J y_{n}\right)=G\left(x^{*},\left(\alpha_{n} J z_{n}+\left(1-\alpha_{n}\right) J x_{n}\right)\right) \\
& =\left\|x^{*}\right\|^{2}-2 \alpha_{n}\left\langle x^{*}, J z_{n}\right\rangle-2\left(1-\alpha_{n}\right)\left\langle x^{*}, J x_{n}\right\rangle+\left\|\alpha_{n} J z_{n}+\left(1-\alpha_{n}\right) J x_{n}\right\|^{2}+2 \rho f\left(x^{*}\right) \\
& \leq\left\|x^{*}\right\|^{2}-2 \alpha_{n}\left\langle x^{*}, J z_{n}\right\rangle-2\left(1-\alpha_{n}\right)\left\langle x^{*}, J x_{n}\right\rangle+\alpha_{n}\left\|J z_{n}\right\|^{2}+\left(1-\alpha_{n}\right)\left\|J x_{n}\right\|^{2}+2 \rho f\left(x^{*}\right) \\
& =\alpha_{n} G\left(x^{*}, J z_{n}\right)+\left(1-\alpha_{n}\right) G\left(x^{*}, J x_{n}\right) \\
& =\left(1-\alpha_{n}\right) G\left(x^{*}, J x_{n}\right)+\alpha_{n} G\left(x^{*},\left(\beta_{n}^{(1)} J x_{0}+\beta_{n}^{(2)} J T_{n} x_{n}+\beta_{n}^{(3)} J S_{n} x_{n}\right)\right) \\
& \leq\left(1-\alpha_{n}\right) G\left(x^{*}, J x_{n}\right) \\
& +\alpha_{n}\left(\left\|x^{*}\right\|^{2}-2 \beta_{n}^{(1)}\left\langle x^{*}, J x_{0}\right\rangle-2 \beta_{n}^{(2)}\left\langle x^{*}, J T_{n} x_{n}\right\rangle-2 \beta_{n}^{(3)}\left\langle x^{*}, J S_{n} x_{n}\right\rangle+\beta_{n}^{(1)}\left\|x_{0}\right\|^{2}\right. \\
& \left.+\beta_{n}^{(2)}\left\|T_{n} x_{n}\right\|^{2}+\beta_{n}^{(3)}\left\|S_{n} x_{n}\right\|^{2}-\beta_{n}^{(2)} \beta_{n}^{(3)} g\left(\left\|J T_{n} x_{n}-J S_{n} x_{n}\right\|\right)+2 \rho f\left(x^{*}\right)\right) \\
& =\left(1-\alpha_{n}\right) G\left(x^{*}, J x_{n}\right)+\alpha_{n}\left(\beta_{n}^{(1)} G\left(x^{*}, J x_{0}\right)+\beta_{n}^{(2)} G\left(x^{*}, J T_{n} x_{n}\right)+\beta_{n}^{(3)} G\left(x^{*}, J S_{n} x_{n}\right)\right. \\
& \left.-\beta_{n}^{(2)} \beta_{n}^{(3)} g\left(\left\|J T_{n} x_{n}-J S_{n} x_{n}\right\|\right)\right) \\
& \leq\left(1-\alpha_{n}\right) G\left(x^{*}, J x_{n}\right)+\alpha_{n}\left(\beta_{n}^{(1)} G\left(x^{*}, J x_{0}\right)+\beta_{n}^{(2)} G\left(x^{*}, J x_{n}\right)+\beta_{n}^{(3)} G\left(x^{*}, J x_{n}\right)\right. \\
& \left.-\beta_{n}^{(2)} \beta_{n}^{(3)} g\left(\left\|J T_{n} x_{n}-J S_{n} x_{n}\right\|\right)\right) \\
& \leq\left(1-\alpha_{n}\right) G\left(x^{*}, J x_{n}\right)+\beta_{n}^{(1)} G\left(x^{*}, J x_{0}\right)+\alpha_{n} G\left(x^{*}, J x_{n}\right) \\
& -\alpha_{n} \beta_{n}^{(2)} \beta_{n}^{(3)} g\left(\left\|J T_{n} x_{n}-J S_{n} x_{n}\right\|\right) \\
& =\beta_{n}^{(1)} G\left(x^{*}, J x_{0}\right)+G\left(x^{*}, J x_{n}\right)-\alpha_{n} \beta_{n}^{(2)} \beta_{n}^{(3)} g\left(\left\|J T_{n} x_{n}-J S_{n} x_{n}\right\|\right) \text {. }
\end{aligned}
$$

It then follows that

$$
\alpha_{n} \beta_{n}^{(2)} \beta_{n}^{(3)} g\left(\left\|J T_{n} x_{n}-J S_{n} x_{n}\right\|\right) \leq \beta_{n}^{(1)} G\left(x^{*}, J x_{0}\right)+G\left(x^{*}, J x_{n}\right)-G\left(x^{*}, J y_{n}\right)
$$


But

$$
\begin{aligned}
G\left(x^{*}, J x_{n}\right)-G\left(x^{*}, J y_{n}\right) & =\left\|x_{n}\right\|^{2}-\left\|y_{n}\right\|^{2}-2\left\langle x^{*}, J x_{n}-J y_{n}\right\rangle \\
& \leq\left|\left\|x_{n}\right\|^{2}-\left\|y_{n}\right\|^{2}\right|+2\left|\left\langle x^{*}, J x_{n}-J y_{n}\right\rangle\right| \\
& \leq\left|\left\|x_{n}\right\|-\left\|y_{n}\right\|\right|\left(\left\|x_{n}\right\|+\left\|y_{n}\right\|\right)+2\left\|x^{*}\right\|\left\|J x_{n}-J y_{n}\right\| \\
& \leq\left\|x_{n}-y_{n}\right\|\left(\left\|x_{n}\right\|+\left\|y_{n}\right\|\right)+2\left\|x^{*}\right\|\left\|J x_{n}-J y_{n}\right\| .
\end{aligned}
$$

From $\lim _{n \rightarrow \infty}\left\|x_{n}-y_{n}\right\|=0$ and $\lim _{n \rightarrow \infty}\left\|J x_{n}-J y_{n}\right\|=0$, we obtain

$$
G\left(x^{*}, J x_{n}\right)-G\left(x^{*}, J y_{n}\right) \longrightarrow 0, \quad n \rightarrow \infty
$$

Using the condition $\lim \inf _{n \rightarrow \infty} \beta_{n}^{(2)} \beta_{n}^{(3)}>0$ and $\alpha_{n} \geq \alpha>0$, we have

$$
\lim _{n \rightarrow \infty} g\left(\left\|J T_{n} x_{n}-J S_{n} x_{n}\right\|\right)=0
$$

By property of $g$, we have $\lim _{n \rightarrow \infty}\left\|J T_{n} x_{n}-J S_{n} x_{n}\right\|=0$. Since $J^{-1}$ is also uniformly norm-tonorm continuous on bounded sets, we have

$$
\lim _{n \rightarrow \infty}\left\|T_{n} x_{n}-S_{n} x_{n}\right\|=0
$$

Furthermore,

$$
\begin{aligned}
\left\|J x_{n}-J z_{n}\right\| & =\left\|J x_{n}-\left(\beta_{n}^{(1)} J x_{0}+\beta_{n}^{(2)} J T_{n} x_{n}+\beta_{n}^{(3)} J S_{n} x_{n}\right)\right\| \\
& =\left\|\beta_{n}^{(1)}\left(J x_{n}-J x_{0}\right)+\beta_{n}^{(2)}\left(J x_{n}-J T_{n} x_{n}\right)+\beta_{n}^{(3)}\left(J x_{n}-J S_{n} x_{n}\right)\right\| \\
& \geq\left\|\beta_{n}^{(2)}\left(J x_{n}-J T_{n} x_{n}\right)+\beta_{n}^{(3)}\left(J x_{n}-J S_{n} x_{n}\right)\right\|-\left\|\beta_{n}^{(1)}\left(J x_{n}-J x_{0}\right)\right\| .
\end{aligned}
$$

This implies that

$$
\left\|\beta_{n}^{(2)}\left(J x_{n}-J T_{n} x_{n}\right)+\beta_{n}^{(3)}\left(J x_{n}-J S_{n} x_{n}\right)\right\| \leq\left\|J x_{n}-J z_{n}\right\|+\beta_{n}^{(1)}\left\|J x_{n}-J x_{0}\right\| .
$$

Since $x_{n} \rightarrow p, z_{n} \rightarrow p$ and $\lim _{n \rightarrow \infty} \beta_{n}^{(1)}=0$, it follows from (3.27) that

$$
\lim _{n \rightarrow \infty}\left\|\beta_{n}^{(2)}\left(J x_{n}-J T_{n} x_{n}\right)+\beta_{n}^{(3)}\left(J x_{n}-J S_{n} x_{n}\right)\right\|=0 .
$$


On the other hand, by using the property of norm, we obtain

$$
\begin{aligned}
\left\|\beta_{n}^{(2)}\left(J x_{n}-J T_{n} x_{n}\right)+\beta_{n}^{(3)}\left(J x_{n}-J S_{n} x_{n}\right)\right\| \\
=\| \beta_{n}^{(2)}\left(J x_{n}-J T_{n} x_{n}\right)+\beta_{n}^{(3)}\left(J x_{n}-J S_{n} x_{n}\right) \\
\quad+\beta_{n}^{(3)}\left(J x_{n}-J T_{n} x_{n}\right)-\beta_{n}^{(3)}\left(J x_{n}-J T_{n} x_{n}\right) \| \\
=\left\|\left(\beta_{n}^{(2)}+\beta_{n}^{(3)}\right)\left(J x_{n}-J T_{n} x_{n}\right)+\beta_{n}^{(3)}\left(J T_{n} x_{n}-J S_{n} x_{n}\right)\right\| \\
\geq\left(\beta_{n}^{(2)}+\beta_{n}^{(3)}\right)\left\|J x_{n}-J T_{n} x_{n}\right\|-\beta_{n}^{(3)}\left\|J T_{n} x_{n}-J S_{n} x_{n}\right\| .
\end{aligned}
$$

This follows that

$$
\left(\beta_{n}^{(2)}+\beta_{n}^{(3)}\right)\left\|J x_{n}-J T_{n} x_{n}\right\| \leq\left\|\beta_{n}^{(2)}\left(J x_{n}-J T_{n} x_{n}\right)+\beta_{n}^{(3)}\left(J x_{n}-J S_{n} x_{n}\right)\right\|+\beta_{n}^{(3)}\left\|J T_{n} x_{n}-J S_{n} x_{n}\right\| .
$$

By (3.27) and $\lim _{n \rightarrow \infty}\left\|J T_{n} x_{n}-J S_{n} x_{n}\right\|=0$, we have

$$
\lim _{n \rightarrow \infty}\left(\beta_{n}^{(2)}+\beta_{n}^{(3)}\right)\left\|J x_{n}-J T_{n} x_{n}\right\|=0
$$

Since $0<b \leq \beta_{n}^{(2)} \leq 1$ and $0<d \leq \beta_{n}^{(3)} \leq 1$, we have

$$
\lim _{n \rightarrow \infty}\left\|x_{n}-T_{n} x_{n}\right\|=0 .
$$

Similarly, we can show that

$$
\lim _{n \rightarrow \infty}\left\|x_{n}-S_{n} x_{n}\right\|=0
$$

Since $x_{n} \rightarrow p$ and $\left\{T_{n}\right\},\left\{S_{n}\right\}$ are uniformly closed, we have $p \in\left(\bigcap_{n=0}^{\infty} F\left(T_{n}\right)\right) \cap\left(\bigcap_{n=0}^{\infty} F\left(S_{n}\right)\right)$.

Finally, we show that $p=\Pi_{F}^{f} x_{0}$. Since $F=\left(\bigcap_{n=0}^{\infty} F\left(T_{n}\right)\right) \cap\left(\bigcap_{n=0}^{\infty} F\left(S_{n}\right)\right)$ is a closed and convex set, from Lemma 2.6, we know that $\Pi_{F}^{f} x_{0}$ is single valued and denote $w=\Pi_{F}^{f} x_{0}$. Since $x_{n}=\Pi_{C_{n}}^{f} x_{0}$ and $w \in F \subset C_{n}$, we have

$$
G\left(x_{n}, J x_{0}\right) \leq G\left(w, J x_{0}\right), \quad \forall n \geq 0 .
$$

We know that $G(\xi, J \varphi)$ is convex and lower semicontinuous with respect to $\xi$ when $\varphi$ is fixed. This implies that

$$
G\left(p, J x_{0}\right) \leq \liminf _{n \rightarrow \infty} G\left(x_{n}, J x_{0}\right) \leq \limsup _{n \rightarrow \infty} G\left(x_{n}, J x_{0}\right) \leq G\left(w, J x_{0}\right) .
$$

From the definition of $\Pi_{F}^{f} x_{0}$ and $p \in F$, we see that $p=w$. This completes the proof. 
Corollary 3.2. Let $E$ be a uniformly convex real Banach space which is also uniformly smooth. Let $C$ be a nonempty, closed, and convex subset of E. Suppose $\left\{T_{n}\right\}_{n=0}^{\infty}$ and $\left\{S_{n}\right\}_{n=0}^{\infty}$ are two countable families of weak relatively nonexpansive mappings of $C$ into itself such that $F:=\left(\bigcap_{n=0}^{\infty} F\left(T_{n}\right)\right) \cap$ $\left(\bigcap_{n=0}^{\infty} F\left(S_{n}\right)\right) \neq \emptyset$. Suppose $\left\{x_{n}\right\}_{n=0}^{\infty}$ is iteratively generated by $x_{0} \in C, C_{0}=C$

$$
\begin{gathered}
z_{n}=J^{-1}\left(\beta_{n}^{(1)} J x_{0}+\beta_{n}^{(2)} J T_{n} x_{n}+\beta_{n}^{(3)} J S_{n} x_{n}\right), \\
y_{n}=J^{-1}\left(\alpha_{n} J z_{n}+\left(1-\alpha_{n}\right) J x_{n}\right), \\
C_{n+1}=\left\{w \in C_{n}: \phi\left(w, y_{n}\right) \leq\left(1-\alpha_{n} \beta_{n}^{(1)}\right) \phi\left(w, x_{n}\right)+\alpha_{n} \beta_{n}^{(1)} \phi\left(w, x_{0}\right)\right\}, \\
x_{n+1}=\Pi_{C_{n+1}} x_{0}, \quad n \geq 0,
\end{gathered}
$$

with the conditions

(i) $\lim _{n \rightarrow \infty} \beta_{n}^{(1)}=0$;

(ii) $0<b \leq \beta_{n}^{(2)} \leq 1,0<d \leq \beta_{n}^{(3)} \leq 1$;

(iii) $0<\alpha \leq \alpha_{n} \leq 1$ for some $\alpha \in(0,1)$.

Then, $\left\{x_{n}\right\}_{n=0}^{\infty}$ converges strongly to $\Pi_{F} x_{0}$.

Proof. Take $f(x)=0$ for all $x \in E$ in Theorem 3.1, $G(\xi, J x)=\phi(\xi, x)$ and $\Pi_{C}^{f} x_{0}=\Pi_{C} x_{0}$. Then, the desired conclusion follows.

Remark 3.3. Our Corollary 3.2 extends and improves on Theorem 1.5. In fact, the iterative procedure (3.36) is simpler than (1.8) in the following two aspects: $(a)$ the process of computing $Q_{n}=\left\{w \in C_{n-1} \cap Q_{n-1}:\left\langle x_{n}-w, J x_{0}-J x_{n}\right\rangle \geq 0\right\}$ is removed; $(b)$ the process of computing $\Pi_{C_{n} \cap Q_{n}}$ is replaced by computing $\Pi_{C_{n}}$.

\section{Applications}

A mapping $H$ from $E$ to $E^{*}$ is said to be

(i) monotone if $\langle H x-H y, x-y\rangle \geq 0$, for all $x, y \in E$;

(ii) strictly monotone if $H$ is monotone and $\langle H x-H y, x-y\rangle=0$ if and only if $x=y$;

(iii) $\beta$-Lipschitz continuous if there exists a constant $\beta \geq 0$ such that $\|H x-H y\| \leq$ $\beta\|x-y\|$, for all $x, y \in E$.

Let $M$ be a set valued mapping from $E$ to $E^{*}$ with domain $D(M)=\{z \in E: M z \neq \emptyset\}$ and range $R(M)=\bigcup\{M z: z \in D(M)\}$. A set-valued mapping $M$ is said to be

(i) monotone if $\left\langle x_{1}-x_{2}, y_{1}-y_{2}\right\rangle \geq 0$ for each $x_{i} \in D(M)$ and $y_{i} \in M x_{i}, i=1,2$,

(ii) $r$-strongly monotone if $\left\langle x_{1}-x_{2}, y_{1}-y_{2}\right\rangle \geq r\left\|x_{1}-x_{2}\right\|^{2}$ for each $x_{i} \in D(M)$ and $y_{i} \in M x_{i}, i=1,2$,

(iii) maximal monotone if $M$ is monotone and its graph $G(M):=\{(x, y): y \in M x\}$ is not properly contained in the graph of any other monotone operator,

(iv) a general $H$-monotone if $M$ is monotone and $(H+\lambda M) E=E^{*}$ holds for every $\ell>0$, where $H$ is a mapping from $E$ to $E^{*}$. 
We denote the set $\{x \in E: 0 \in M x\}$ by $M^{-1} 0$. From Li et al. [15], we know that if $H: E \rightarrow E^{*}$ is strictly monotone and $M: E \rightarrow 2^{E^{*}}$ is general $H$-monotone mapping, then $M^{-1} 0$ is closed and convex. Furthermore, for every $\lambda>0$ and $x^{*} \in E^{*}$, there exists a unique $x \in D(M)$ such that $x=(H+\lambda M)^{-1} x^{*}$. Thus, we can define a single-value mapping $T_{\lambda}: E \rightarrow D(M)$ by $T_{\lambda} x=(H+\lambda M)^{-1} H x$. It is obvious that $M^{-1} 0=F\left(T_{\lambda}\right)$ for all $\lambda>0$.

Lemma 4.1 (Alber, [16]). If $E$ is a uniformly convex and uniformly smooth Banach space, $\delta_{E}(\epsilon)$ is the modulus of convexity of $E$ and $\rho_{E}(t)$ is the modulus of smoothness of $E$, then the inequalities

$$
8 d^{2} \delta_{E}\left(\frac{\|x-\xi\|}{4 d}\right) \leq \phi(x, \xi) \leq 4 d^{2} \rho_{E}\left(\frac{4\|x-\xi\|}{d}\right)
$$

hold for all $x$ and $\xi$ in $E$, where $d=\sqrt{\left(\|x\|^{2}+\|\xi\|^{2}\right) / 2}$.

Lemma 4.2 (Xia and Huang, [22]). Let $E$ be a Banach space with dual space $E^{*}, H: E \rightarrow E^{*} a$ strictly monotone mapping and $M: E \rightarrow 2^{E^{*}}$ a general $H$-monotone mapping. Then

(i) $(H+\lambda M)^{-1}$ is a single valued mapping;

(ii) if $E$ is reflexive and $M: E \rightarrow 2^{E^{*}}$ is r-strongly monotone, $(H+\lambda M)^{-1}$ is Lipschitz continuous with constant $1 /(\lambda r)$, where $r>0$.

Theorem 4.3. Let $E$ be a uniformly convex real Banach space which is also uniformly smooth with $\delta_{E}(\epsilon) \geq k \epsilon^{2}$ and $\rho_{E}(t) \leq c t^{2}$ for some $k, c>0$. Suppose $H: E \rightarrow E^{*}$ is a strictly monotone and $\beta$-Lipschitz continuous mapping and $M_{i}: E \rightarrow 2^{E^{*}}$ is a general H-monotone mapping and $r_{i}$-strongly monotone mapping with $r_{i}>0, i=1,2$ such that $F:=M_{1}^{-1} 0 \cap M_{2}^{-1} 0 \neq \emptyset$. Let $T_{\lambda}^{M_{i}}=\left(H+\lambda M_{i}\right)^{-1} H, i=1,2$ and $f: E \rightarrow \mathbb{R}$ be a convex and lower semicontinuous mapping with $D(f)=E$ and suppose for each $n \geq 0$, there exists a $\lambda_{n}>0$ such that $64 c \beta^{2} \leq$ $\min \left\{(1 / 2) k \lambda_{n}^{2} r_{1}^{2},(1 / 2) k \lambda_{n}^{2} r_{1}^{2}\right\}$. Let $\left\{x_{n}\right\}_{n=0}^{\infty}$ be iteratively generated by $x_{0} \in E, C_{0}=E$,

$$
\begin{gathered}
z_{n}=J^{-1}\left(\beta_{n}^{(1)} J x_{0}+\beta_{n}^{(2)} J T_{\lambda_{n}}^{M_{1}} x_{n}+\beta_{n}^{(3)} J T_{\lambda_{n}}^{M_{2}} x_{n}\right), \\
y_{n}=J^{-1}\left(\alpha_{n} J x_{n}+\left(1-\alpha_{n}\right) J z_{n}\right), \\
C_{n+1}=\left\{w \in C_{n}: G\left(w, J y_{n}\right) \leq\left(1-\alpha_{n} \beta_{n}^{(1)}\right) G\left(w, J x_{n}\right)+\alpha_{n} \beta_{n}^{(1)} G\left(w, J x_{0}\right)\right\}, \\
x_{n+1}=\prod_{C_{n+1}}^{f} x_{0}, \quad n \geq 0,
\end{gathered}
$$

with the conditions

(i) $\lim _{n \rightarrow \infty} \beta_{n}^{(1)}=0$;

(ii) $0<b \leq \beta_{n}^{(2)} \leq 1,0<d \leq \beta_{n}^{(3)} \leq 1$;

(iii) $0<\alpha \leq \alpha_{n} \leq 1$ for some $\alpha \in(0,1)$;

(iv) $\lim \inf _{n \rightarrow \infty} \lambda_{n}>0$.

Then, $\left\{x_{n}\right\}_{n=0}^{\infty}$ converges strongly to $\prod_{F}^{f} x_{0}$. 
Proof. We only need to prove that $\left\{T_{\lambda_{n}}^{M_{1}}\right\}$ and $\left\{T_{\lambda_{n}}^{M_{2}}\right\}$ are countable families of weak relatively nonexpansive mappings with common fixed points sets $\bigcap_{n=0}^{\infty} F\left(T_{\lambda_{n}}^{M_{1}}\right)=M_{1}^{-1} 0$ and $\bigcap_{n=0}^{\infty} F\left(T_{\lambda_{n}}^{M_{2}}\right)=M_{2}^{-1} 0$, respectively. Firstly, we have $\bigcap_{n=0}^{\infty} F\left(T_{\lambda_{n}}^{M_{1}}\right)=M_{1}^{-1} 0 \neq \emptyset$. Secondly, we show that $\phi\left(p, T_{\lambda_{n}}^{M_{1}} w\right) \leq \phi(p, w)$, for all $w \in E, p \in F\left(T_{\lambda_{n}}^{M_{1}}\right), n \geq 0$. Now, by Lemma 4.2 and the Lipschitz continuity of $H$, we have

$$
\begin{aligned}
\left\|T_{\lambda_{n}}^{M_{1}} p-T_{\lambda_{n}}^{M_{1}} w\right\| & =\left\|\left(H+\lambda_{n} M_{1}\right)^{-1} H p-\left(H+\lambda_{n} M_{1}\right)^{-1} H w\right\| \\
& \leq \frac{1}{\lambda_{n} r_{1}}\|H p-H w\| \\
& \leq \frac{\beta}{\lambda_{n} r_{1}}\|p-w\| .
\end{aligned}
$$

By (4.3) and Lemma 4.1,

$$
\begin{aligned}
\phi\left(p, T_{\lambda_{n}}^{M_{1}} w\right) & =\phi\left(T_{\lambda_{n}}^{M_{1}} p, T_{\lambda_{n}}^{M_{1}} w\right) \\
& \leq 4 d^{2} \rho_{E}\left(\frac{4\left\|T_{\lambda_{n}}^{M_{1}} p-T_{\lambda_{n}}^{M_{1}} w\right\|}{d}\right) \\
& \leq 64 c\left\|T_{\lambda_{n}}^{M_{1}} p-T_{\lambda_{n}}^{M_{1}} w\right\|^{2} \\
& \leq \frac{64 c \beta^{2}}{\lambda_{n}^{2} r_{1}^{2}}\|p-w\|^{2}, \\
\phi(p, w) & \geq 8 d^{2} \delta_{E}\left(\frac{\|p-w\|}{4 d}\right) \geq \frac{1}{2} k\|p-w\|^{2} .
\end{aligned}
$$

Since $64 c \beta^{2} \leq(1 / 2) k \lambda_{n}^{2} r_{1}^{2}$, it follows from (4.4) that $\phi\left(p, T_{\lambda_{n}}^{M_{1}} w\right) \leq \phi(p, w)$, for all $w \in E, p \in$ $F\left(T_{\lambda_{n}}^{M_{1}}\right), \quad n \geq 0$. Thirdly, we show that $\widetilde{F}\left(\left\{T_{\lambda_{n}}^{M_{1}}\right\}\right)=\bigcap_{n=0}^{\infty} F\left(T_{\lambda_{n}}^{M_{1}}\right)=M_{1}^{-1} 0$. We first show that $\tilde{F}\left(\left\{T_{\lambda_{n}}^{M_{1}}\right\}\right) \subset M_{1}^{-1} 0$. Let $p \in \tilde{F}\left(\left\{T_{\lambda_{n}}^{M_{1}}\right\}\right)$, then there exists $\left\{x_{n}\right\} \subset E$ such that $x_{n} \rightarrow p$ and $\lim _{n \rightarrow \infty}\left\|x_{n}-T_{\lambda_{n}}^{M_{1}} x_{n}\right\|=0$. Since $H$ is $\beta$-Lipschitz continuous,

$$
\left\|H x_{n}-H T_{\lambda_{n}}^{M_{1}} x_{n}\right\| \leq \beta\left\|x_{n}-T_{\lambda_{n}}^{M_{1}} x_{n}\right\|
$$

Letting $n \rightarrow \infty$, we obtain

$$
\frac{1}{\lambda_{n}}\left(H x_{n}-H T_{\lambda_{n}}^{M_{1}} x_{n}\right) \longrightarrow 0
$$


It follows from $\left(1 / \lambda_{n}\right)\left(H x_{n}-H T_{\lambda_{n}}^{M_{1}} x_{n}\right) \in M_{1} T_{\lambda_{n}}^{M_{1}} x_{n}$ and the monotonicity of $M_{1}$ that

$$
\left\langle x-T_{\lambda_{n}}^{M_{1}} x_{n}, x^{*}-\frac{1}{\lambda_{n}}\left(H x_{n}-H T_{\lambda_{n}}^{M_{1}} x_{n}\right)\right\rangle \geq 0
$$

for all $x \in D\left(M_{1}\right)$ and $x^{*} \in M_{1} x$. Taking the limit as $n \rightarrow \infty$, we obtain

$$
\left\langle x-p, x^{*}\right\rangle \geq 0
$$

for all $x \in D\left(M_{1}\right)$ and $x^{*} \in M_{1} x$. By the maximality of $M_{1}$, we know that $p \in M_{1}^{-1} 0$. On the other hand, we know that $F\left(T_{\lambda_{n}}^{M_{1}}\right)=M_{1}^{-1} 0, F\left(T_{\lambda_{n}}^{M_{1}}\right) \subset \widetilde{F}\left(T_{\lambda_{n}}^{M_{1}}\right)$ for all $n \geq 0$, therefore, $M_{1}^{-1} 0=\bigcap_{n=0}^{\infty} F\left(T_{\lambda_{n}}^{M_{1}}\right)=\tilde{F}\left(\bigcap_{n=0}^{\infty} T_{\lambda_{n}}^{M_{1}}\right)$. Thus, we have proved that $\left\{T_{\lambda_{n}}^{M_{1}}\right\}$ is a countable family of weak relatively nonexpansive mappings with common fixed points sets $\bigcap_{n=0}^{\infty} F\left(T_{\lambda_{n}}^{M_{1}}\right)=$ $M_{1}^{-1} 0$. By following the same arguments, we can show that $\left\{T_{\lambda_{n}}^{M_{2}}\right\}$ is a countable family of weak relatively nonexpansive mappings with common fixed points sets $\bigcap_{n=0}^{\infty} F\left(T_{\lambda_{n}}^{M_{2}}\right)=M_{2}^{-1} 0$.

Let $E$ be a uniformly convex and uniformly smooth Banach space, $H=J$ and $M$ be a maximal monotone mapping. Then, we can define $J_{\lambda}=(J+\lambda M)^{-1} J$ for all $\lambda>0$. We know that $J_{\lambda}$ is relatively nonexpansive and therefore weak relatively nonexpansive and $M^{-1} 0=F\left(J_{\lambda}\right)$ for all $\lambda>0$ (see, e.g., [2]), where $F\left(J_{\lambda}\right)$ denotes the fixed points set of $J_{\lambda}$. By Corollary 3.2, we obtain the following theorem.

Theorem 4.4. Let $E$ be a uniformly convex real Banach space which is also uniformly smooth. For each $i=1,2$, let $M_{i} \subset E \times E^{*}$ be a maximal monotone operator and let $J_{\lambda}^{M_{i}}=\left(J+\lambda M_{i}\right)^{-1} J$ for all $\lambda>0$ and suppose $C$ is a nonempty closed and convex subset of $E$ such that $D\left(M_{i}\right) \subset C \subset J^{-1}\left(\bigcap_{\lambda>0} R(J+\right.$ $\left.\lambda M_{i}\right)$ ) and $F:=M_{1}^{-1} 0 \cap M_{2}^{-1} 0 \neq \emptyset$. Let $\left\{x_{n}\right\}_{n=0}^{\infty}$ be iteratively generated by $x_{0} \in E, C_{0}=E$,

$$
\begin{gathered}
z_{n}=J^{-1}\left(\beta_{n}^{(1)} J x_{0}+\beta_{n}^{(2)} J J T_{\lambda_{n}}^{M_{1}} x_{n}+\beta_{n}^{(3)} J J T_{\lambda_{n}}^{M_{2}} x_{n}\right), \\
y_{n}=J^{-1}\left(\alpha_{n} J x_{n}+\left(1-\alpha_{n}\right) J z_{n}\right), \\
C_{n+1}=\left\{w \in C_{n}: \phi\left(w, y_{n}\right) \leq\left(1-\alpha_{n} \beta_{n}^{(1)}\right) \phi\left(w, x_{n}\right)+\alpha_{n} \beta_{n}^{(1)} \phi\left(w, x_{0}\right)\right\}, \\
x_{n+1}=\prod_{C_{n+1}} x_{0}, \quad n \geq 0,
\end{gathered}
$$

with the conditions

(i) $\lim _{n \rightarrow \infty} \beta_{n}^{(1)}=0$;

(ii) $0<b \leq \beta_{n}^{(2)} \leq 1,0<d \leq \beta_{n}^{(3)} \leq 1$;

(iii) $0<\alpha \leq \alpha_{n} \leq 1$ for some $\alpha \in(0,1)$;

(iv) $\lim \inf _{n \rightarrow \infty} \lambda_{n}>0$.

Then, $\left\{x_{n}\right\}_{n=0}^{\infty}$ converges strongly to $\prod_{F} x_{0}$. 


\section{Acknowledgment}

The author would like to express his thanks to Professor Jean Pierre Gossez and the referees for their valuable suggestions and comments.

\section{References}

[1] C. Chidume, Geometric Properties of Banach Spaces and Nonlinear Iterations, vol. 1965 of Lecture Notes in Mathematics, Springer, London, UK, 2009.

[2] W. Takahashi, Nonlinear Functional Analysis-Fixed Point Theory and Application, Yokohama Publishers, Yokohama, Japan, 2000.

[3] W. Takahashi, Nonlinear Functional Analysis, Yokohama Publishers, Yokohama, Japan, 2000.

[4] S. Kamimura and W. Takahashi, "Strong convergence of a proximal-type algorithm in a Banach space," SIAM Journal on Optimization, vol. 13, no. 3, pp. 938-945, 2002.

[5] Y. Su, H.-K. Xu, and X. Zhang, "Strong convergence theorems for two countable families of weak relatively nonexpansive mappings and applications," Nonlinear Analysis. Theory, Methods $\mathcal{E}$ Applications, vol. 73, no. 12, pp. 3890-3906, 2010.

[6] D. Butnariu, S. Reich, and A. J. Zaslavski, "Asymptotic behavior of relatively nonexpansive operators in Banach spaces," Journal of Applied Analysis, vol. 7, no. 2, pp. 151-174, 2001.

[7] D. Butnariu, S. Reich, and A. J. Zaslavski, "Weak convergence of orbits of nonlinear operators in reflexive Banach spaces," Numerical Functional Analysis and Optimization, vol. 24, no. 5-6, pp. 489-508, 2003.

[8] Y. Censor and S. Reich, "Iterations of paracontractions and firmly nonexpansive operators with applications to feasibility and optimization," Optimization, vol. 37, no. 4, pp. 323-339, 1996.

[9] S.-Y. Matsushita and W. Takahashi, "A strong convergence theorem for relatively nonexpansive mappings in a Banach space," Journal of Approximation Theory, vol. 134, no. 2, pp. 257-266, 2005.

[10] X. Qin and Y. Su, "Strong convergence theorems for relatively nonexpansive mappings in a Banach space," Nonlinear Analysis. Theory, Methods E Applications, vol. 67, no. 6, pp. 1958-1965, 2007.

[11] W. Takahashi and K. Zembayashi, "Strong convergence theorem by a new hybrid method for equilibrium problems and relatively nonexpansive mappings," Fixed Point Theory and Applications, vol. 2008, Article ID 528476, 11 pages, 2008.

[12] J. Kang, Y. Su, and X. Zhang, "Hybrid algorithm for fixed points of weak relatively nonexpansive mappings and applications," Nonlinear Analysis. Hybrid Systems, vol. 4, no. 4, pp. 755-765, 2010.

[13] H. Zegeye and N. Shahzad, "Strong convergence theorems for a finite family of asymptotically nonexpansive mappings and semigroups," Nonlinear Analysis. Theory, Methods \& Applications, vol. 69, no. 12, pp. 4496-4503, 2008.

[14] S. Plubtieng and K. Ungchittrakool, "Strong convergence theorems for a common fixed point of two relatively nonexpansive mappings in a Banach space," Journal of Approximation Theory, vol. 149, no. 2, pp. 103-115, 2007.

[15] X. Li, N.-J. Huang, and D. O'Regan, "Strong convergence theorems for relatively nonexpansive mappings in Banach spaces with applications," Computers E Mathematics with Applications, vol. 60, no. 5, pp. 1322-1331, 2010.

[16] Y. I. Alber, "Metric and generalized projection operators in Banach spaces: properties and applications," in Theory and Applications of Nonlinear Operators of Accretive and Monotone Type, vol. 178 of Lecture Notes in Pure and Applied Mathematics, pp. 15-50, Marcel Dekker, New York, NY, USA, 1996.

[17] Y. I. Alber and S. Reich, "An iterative method for solving a class of nonlinear operator equations in Banach spaces," Panamerican Mathematical Journal, vol. 4, no. 2, pp. 39-54, 1994.

[18] I. Cioranescu, Geometry of Banach Spaces, Duality Mappings and Nonlinear Problems, vol. 62 of Mathematics and its Applications, Kluwer Academic, Dordrecht, The Netherlands, 1990.

[19] K.-Q. Wu and N.-J. Huang, "The generalised $f$-projection operator with an application," Bulletin of the Australian Mathematical Society, vol. 73, no. 2, pp. 307-317, 2006.

[20] J. Fan, X. Liu, and J. Li, "Iterative schemes for approximating solutions of generalized variational inequalities in Banach spaces," Nonlinear Analysis. Theory, Methods \& Applications, vol. 70, no. 11, pp. 3997-4007, 2009. 
[21] Y. J. Cho, H. Zhou, and G. Guo, "Weak and strong convergence theorems for three-step iterations with errors for asymptotically nonexpansive mappings," Computers \& Mathematics with Applications, vol. 47, no. 4-5, pp. 707-717, 2004.

[22] F.-Q. Xia and N.-J. Huang, "Variational inclusions with a general $H$-monotone operator in Banach spaces," Computers \& Mathematics with Applications, vol. 54, no. 1, pp. 24-30, 2007. 


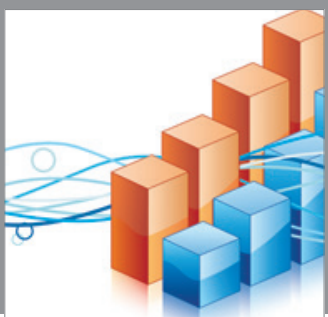

Advances in

Operations Research

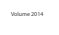

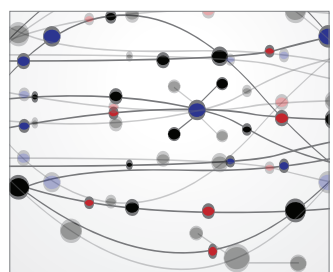

\section{The Scientific} World Journal
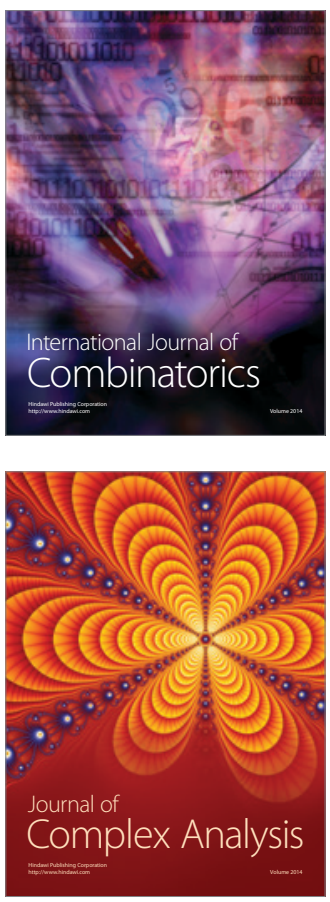

International Journal of

Mathematics and

Mathematical

Sciences
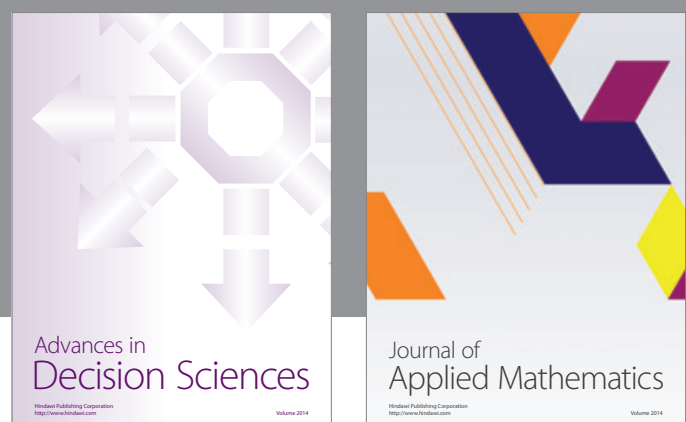

Journal of

Applied Mathematics
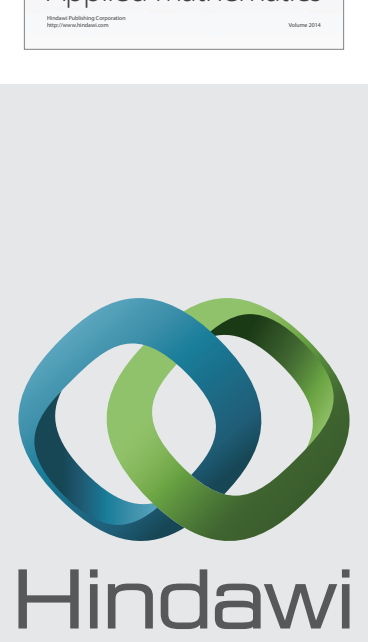

Submit your manuscripts at http://www.hindawi.com
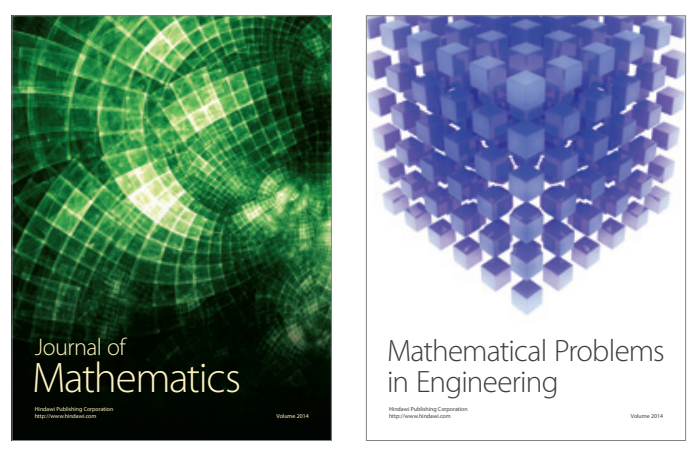

Mathematical Problems in Engineering
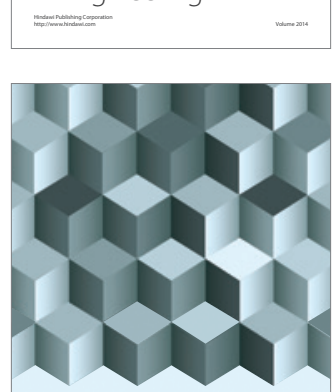

Journal of

Function Spaces
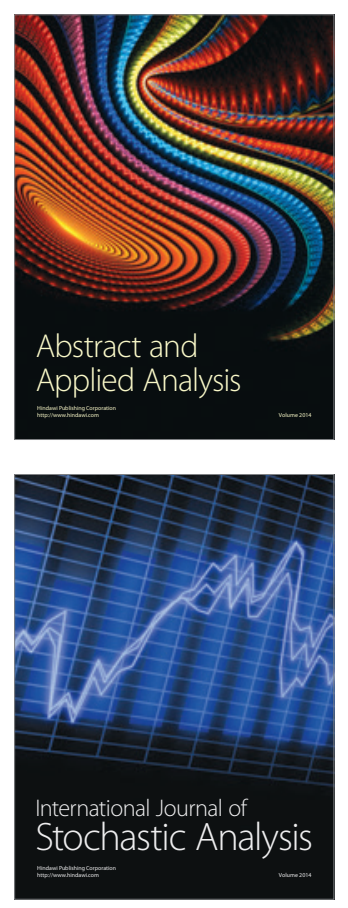

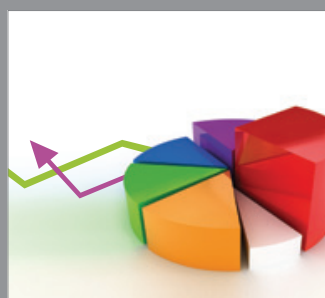

ournal of

Probability and Statistics

Promensencen
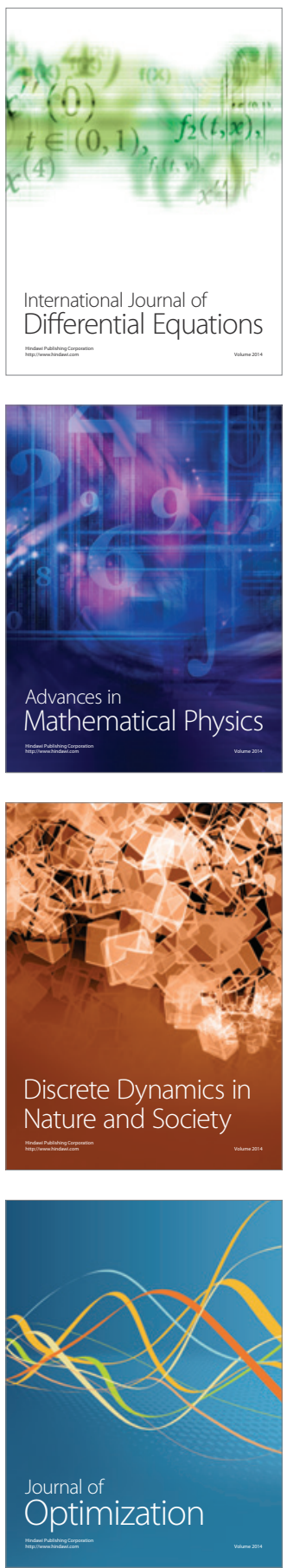